\title{
How the Learning Story Framework can be Enhanced to Provide Better Assessment Information to Support Planning for Children's Further Learning: A Critique of the Reliability and Formative Validity of Learning Stories in Aotearoa New Zealand
}

\author{
Louise Wanoa and Michael Johnston \\ School of Education, Victoria University of Wellington
}

\begin{abstract}
Learning stories are the predominant method of assessment in the Aotearoa/New Zealand early childhood education sector. In the present paper, we argue that, while learning stories appropriately emphasise what children can already do, also describing their challenges in learning stories could contribute to planning, independent learning, motivation and self-assessment. Drawing on the first author's professional experience as an early childhood teacher, a critique of the three components of learning stories' practice - notice, recognise, and respond - is used to put forward a case for effective strategies to enhance the validity and reliability of these assessments. These components are deployed sequentially in the learning stories assessment process to serve the formative purpose of the approach. The notice component includes a familiar observer, informal sharing of observations and watchful listening to achieve descriptive validity, and the use of children's own words to achieve interpretative validity. The 'recognise' component involves peer review, multiple perspectives, and child plus parental feedback to achieve construct validity. The 'respond' component draws attention to multiple perspectives input to achieve accuracy as a property of validity. The application of each strategy also improves the reliability of learning story assessments.
\end{abstract}

Keywords: Learning Stories, Assessment, Early Childhood, Validity, Reliability

\section{Introduction}

Do you know my story? Do you understand my story? Do you get where I am going with my story? These are the questions children implicitly ask in their everyday learning experiences. Learning stories, the predominant assessment approach for early childhood education (ECE) in Aotearoa/New Zealand (NZ) (Blaiklock, 2011; Cameron, 2014, 2018; Cameron, McLachlan, \& Rawlins, 2016; Eden, 2015; Ministry of Education [MoE], 2004a; Mitchell, 2008; Zhang, 2017), are designed to tell children's stories in a way that elucidates answers to these questions.

Learning stories were developed by Professor Margaret Carr (e.g., Carr 1998, 2001) as a tool for assessing and planning young children's learning (Blaiklock, 2008, 2011; Eden, 2015; MoE, 2004a; Zhang, 2017). The learning story approach is dynamic, formative and qualitative in nature. It is narrative in style and based in sociocultural theory (Cameron, 2014; Carr \& Lee, 2019; Cowie \& Carr, 2017; MoE, 2017). The sociocultural basis of learning stories, derived from Vygotsky (1978), is that they promote a view of learning as being a progressive journey, unique to each child (MoE, 2017). Learning stories emphasise the learning journey itself 
rather than specific 'outcomes' or 'goals', with children as active learners and purposeful communicators (Carr, 2001). Even so, learning stories are intended to be used formatively; they map children's engagement with valued learning activities with people, places and objects that influence the directions they take in their development (Cameron, 2014; Carr, 2001; Carr \& Lee, 2019; MoE, 2017).

A recently updated version of NZ's early childhood curriculum, Te Whāriki (MoE, 2017), provides revised assessment guidance. Whilst the assessment revision states that assessment should be both spur-of-the-moment and intentional (Cameron, 2018), it does not position learning stories as the only way to ascertain "what children know and can do, what interests them, how they are progressing, what new learning opportunities are suggested, and where additional support may be required" (MoE, 2017, p. 63).

Although the revised assessment guidance in Te Whāriki gives explicit support for utilising various ECE assessment tools - e.g., checklists, running records, sociograms, and own tests (Cameron, 2018) - the findings from two eminent nationwide surveys of ECE teachers' practice conducted by Mitchell (2008) and Cameron (2018) demonstrate that over the last decade the learning story framework has been the most commonly used assessment tool within ECE services. It is, therefore, pertinent to re-examine the learning story method as an unwaveringly popular assessment approach currently operating in NZ's ECE sector.

A central criterion for judging the utility of, and ethical basis for an assessment approach is that of validity (See Snow \& Van Hemel, 2008 for further discussion on the utility of the term in relation to ECE assessments). The concept of validity has been formulated, debated, and reformulated for many decades (see Newton \& Shaw, 2014 for a history, and Snow \& Van Hemel, 2008 for a discussion in relation to ECE assessment). Despite the nuance and sophistication that scholarly work has brought to the concept, it is often defined rather simplistically. For example, on Te Kete Ipurangi, a teachers' resource website provided by the NZ MoE, validity is defined as "the extent to which [an assessment] measures what it was designed to measure, without contamination from other characteristics" (Te Kete Ipurangi, n.d.). The difficulty with this kind of definition of validity is that it does not make explicit that assessment is used for different purposes and an assessment that is valid for one purpose might not be for another.

Another definition, which does take purpose into account, is as follows: The validity of an assessment process is the extent to which that process can be used to make the intended educational inferences without negatively impacting on teaching and learning (see Newton \& Shaw, 2014). This is the definition that will be used in the present work to critique the validity of learning stories.

We note that the term validity is somewhat controversial in the ECE assessment literature, with some authors preferring terminology such as trustworthiness, authenticity and manageability (e.g., Absolum, 2011). While we acknowledge these preferences, we note that all of these terms are essentially subsumed by the definition of validity we are adopting for the present purposes: an assessment that is not trustworthy or authentic cannot be used to make educational inferences; one that is not manageable is likely to have a negative impact on teaching and learning. Furthermore, the term validity has long-standing currency in the assessment literature (see Snow \& Van Hemel, 2008), notwithstanding reservations about its use in the ECE sector. For all of these reasons, we see it as an appropriate term for our present purposes.

As noted above, the learning story process is intended to be formative in nature. Formative assessment (assessment for learning) involves observing a child's learning process, 
recognising what they have already learned and responding in a way that facilitates further learning (Carr \& Lee, 2019; MoE, 2004a, 2017). The MoE (2004a, p. 6) expanded Drummond's definition of formative assessment by adding in brackets: "we [children, families, teachers, and others] observe children's learning [notice], strive to understand it [recognise], and then put our understanding to good use [respond]" (Drummond, 1993, p. 13).

Learning stories are consonant with this definition in as much as they describe children's strengths by noticing, recognising and responding to what they can do (MoE, 2017), as opposed to noting what they cannot (yet) do (Lepper, Williamson, \& Cullen, 2003). Thus, learning stories take a 'credit' approach to the understanding of learning (Lepper et al., 2003; Mitchell, 2008). This strengths-based model aligns with the early childhood curriculum, Te Whāriki (Cameron, 2018) which positions children as capable and confident learners (MoE, 2017).

The explicit eschewal, under the learning stories approach, of noting learning goals that children have yet to achieve is less consonant with Drummond's (1993) definition of formative assessment. In order to "put our understanding [of children's learning] to good use" (p. 13) - that is, to use our understanding to facilitate further learning - the challenges that children encounter in their learning, as well as strengths must be acknowledged (see Cameron, 2018). A teacher who sees the best in children embraces the whole child, not just a partial picture. To do so means not only observing what a child can do already, but noting what a child cannot yet do in order to fully plan further areas of opportunities to support, guide and encourage a child to reach their full potential (Forman \& Hall, 2013). Children operating in a zone of proximal development (see Vygotsky, 1978) will, by definition, encounter learning challenges that they are not yet fully equipped to meet. An assessment focus that does not document these challenges, but is confined to recording children's strengths may not, therefore, optimise their continued growth (Cameron, 2018; Dunn, 2004). For example, a teacher may inaccurately or mistakenly infer from a purely 'strengths-based' record that a concept or skill has been mastered and then make a decision to move the facilitation of learning to a new area. An incompletely learned concept or skill may then diminish due to inadequate reinforcement or may not be well enough embedded to support further learning, thereby restricting progress.

Williamson, Cullen, and Lepper (2006) raise an apparent dilemma in this regard: how to use learning stories to make visible, children's learning challenges, while not compromising a positive emphasis on their interests, strengths and capabilities. It is important to address this question; teachers have a responsibility to respond to children's difficulties and challenges in learning, and assessment should not restrict progress in learning (Williamson et al., 2006) but enhance it (MoE, 2017). In this paper, we suggest a way in which to incorporate in learning stories children's current challenges without compromising the strengths-based model, in order to optimise the positive impact of learning stories on planning for further learning.

\section{Validity and reliability in relation to learning stories}

Validity and reliability are fundamental concepts for ensuring that assessment information can be used to support sound educational decision-making. Demonstrating that the learning stories assessment process is valid and reliable is therefore important for our confidence and trust in learning stories as a means of planning for learners' growth and development. 
Recently, concerns have been raised about both the validity of learning stories - the extent to which they can support useful inferences about children's learning - and also their reliability - the degree of consistency with which teachers construct learning stories from observational evidence (Blaiklock, 2008, 2010; see also Snow \& Van Hemel, 2008). If learning stories are to make the strongest contributions possible to children's development, these concerns must be addressed.

Learning stories comprise a much less structured approach to assessment than more conventional methods (see Blaiklock, 2008, 2010). Blaiklock (2008) notes that ECE teachers do not assess learning using quantitative measures because each child is to be treated as unique, developing at their own pace and following their own learning path. Thus, normative thinking, commonly associated with quantitative assessment, is avoided on the grounds that it would undermine the philosophy that individuals are engaged in unique learning journeys and shape their own identities (Carr, 2001; Carr \& Lee, 2019). In accordance with this philosophy, learning stories are narrative in style, meaning they are descriptive (Cameron, 2014) and interpretative (Carr, 2001; Carr \& Lee, 2019).

Under the narrative approach of learning stories, concepts such as credibility (trustworthiness) and plausibility (see Carr, 2001; Johnson \& Christensen, 2017; Maxwell, 2013) are generally used in preference to the concepts of validity and reliability, which are ubiquitous in other assessment literature. In fact, however, the latter terms are perfectly consonant with those that are more specific to ECE assessment. Strategies such as using multiple observers, peer review, member checks and feedback, participants' words (quotations), multiple perspectives and triangulation (Johnson \& Christensen, 2017; Maxwell, 2013) are typically used to establish credibility and plausibility, supported by both New Zealand based (e.g., Cameron, 2014, 2018; Hooker, 2015) and international (e.g., Macy, Bagnato, \& Gallen, 2016; Snow \& Van Hemel, 2008) research. Such strategies enhance both the extent to which inferences about teaching and learning can be made on the basis of an assessment (validity) and the consistency of judgements (reliability). Thus, while it is true that the statistical techniques used to measure validity and reliability cannot be used with narrative assessment, the concepts themselves remain perfectly applicable. We therefore argue for terminological consistency with the rest of the assessment literature, while recognising that approaches to establishing validity and reliability must necessarily be somewhat different for learning stories than for quantitative assessment.

However, to be effective for formative purposes, the learning stories approach must be adapted to include reference to children's current learning challenges, as well as their strengths and achievements. We do not set out to ascertain the extent to which ECE teachers utilise the above strategies (see Cameron's 2018 study), rather the objective is to provide teachers with tools to derive guidelines that they can implement in their own settings to strengthen the effectiveness of the three required components - notice, recognise, and respond (MoE, 2004a) - of the learning story framework.

\section{Notice - Do you know my story?}

The first component in the framework of the learning story approach - Notice - is usually written in the first person (Zhang, 2017), e.g., "Aaron, I noticed you...", addressed to the child and his or her parents (Carr \& Lee, 2019). This component includes a description of the learning environment, what is happening and with whom (peers or teachers), what the teacher thinks a child is doing, feeling and thinking, and placing the child (as the main character) at the heart of the story (Hazard, 2011). Data gathering methods include 
observations of a child engaged in a specific activity (Blaiklock, 2008, 2011; Cameron, 2018; MoE, 2017) with annotated photos (Cameron, 2018; Mitchell, 2008; MoE, 2017; Zhang, 2017) which may be supported by examples of the child's work (Cameron, 2018; Mitchell, 2008) such as art pictures (MoE, 2017), written letters or numbers (Carr \& Lee, 2019). Observations are conducted naturalistically in the educational setting, with a focus on a child as an active participant interacting with people (learning community - peers, teachers and family), places (environment) and things (activities, materials and artefacts) in that setting (Blaiklock, 2008; Carr \& Claxton, 2002; Cowie \& Carr, 2017).

Although the key foci of documenting observations are on a child's interests, strengths and capabilities, the learning challenges a child encounters could also be incorporated into their story by noting what a child does when faced with difficulty; for example, "whether he or she avoids the situation, repeats an unsuccessful approach many times, tries a different way to tackle things, or calls for adult help" (Dunn, 2000, p. 78). To avoid compromising the strength-based model, challenges could be positioned in the background with a positive focus on interests, strengths and capabilities in the foreground (for example, see Carr \& Lee, 2019, pp. 29, 55-57; Williamson et al., 2006) of a child's story. Dunn (2000) has argued that it is important to do it this way on the grounds that every child, with or without special needs, has a right for their strengths to be acknowledged first and foremost rather than the focus being on their shortcomings or "what they cannot do" (Mitchell, 2008, p. vii). Nonetheless, interweaving challenges in the background of a story would make it much clearer, more complete and - most importantly - more effective in supporting further learning, than one that documents only strengths and achievements.

The incorporation of challenges alongside interests, strengths and capabilities in a child's story would contribute to "the authenticity of the content" (Eden, 2015, p. 166). Not least amongst the audience for such authenticity are children themselves; children are entitled to be represented accurately in learning stories. While it is arguably appropriate to emphasise achievements and strengths, as Dunn (2000) argued, it is also essential that children build resilience and persistence in the face of challenges. Having educators acknowledge the existence of challenges in a supportive, encouraging way, as a basis for involving children in making plans to meet such challenges, would support children in this regard.

If documenting challenges in learning stories is to support children in establishing resilience and to provide effective formative information, the observations made by teachers need to be reliable (trustworthy). As noted above, one of the ways in which reliability can be established is by using multiple observers. However, there are a number of considerations that can make this challenging in the ECE context. To build up a true picture of development and learning, a child must know and feel comfortable in the presence of their observer; Dunn (2000) argued that validity is enhanced when observations are conducted by people the child knows well, i.e., teachers and parents, noting though that "behaviour is less likely to be distorted by the presence of a comparative stranger" (p. 76). This implies that the familiarity of an observer is an important factor for a narrative assessment such as a learning story, according to the MoE (2017), to be valid; as one teacher interviewed by Cameron (2018) articulated: "Knowing the children is a big part. What's important to them at the time. What's important to their family" (p. 168).

In practice, however, observations for learning stories are usually carried out and written up by one person. Hence, when and where these observations take place and what types of learning experience are documented is up to individual teachers (Blaiklock, 2008). 
This self-evidently calls into question the authenticity of content in that there is no source of corroborating observation or interpretation (Johnson \& Christensen, 2017). If two or more people conducted the exercise, estimates of reliability would become possible. However, use of multiple observers to cross-check information is not typically practical in the ECE setting both because adult-child ratio requirements make it unfeasible and because it would take valuable time away from teaching moments with other children. Furthermore, in many ECE settings there are a limited number of educators with whom individual children are familiar. In light of Dunn's (2000) observation that children may not manifest certain learning behaviour in the presence of strangers, this also limits possibilities for establishing reliability through multiple observations.

Determining critical moments to observe, therefore, is usually in the hands of individual teachers. However, teachers can informally share with fellow teachers the thoughts, feelings and developmental expectations arising from their observations of children's learning (Hazard, 2011) and then make this explicit in a learning story (a form of triangulation). Examples of this are taken from learning stories written by the first author:

1. Your journey began, as Colleen ${ }^{1}$ (another teacher) explained when you practised writing your name the week before by copying one that was written out for you. Today you did it all by yourself!

2. Ella, your teacher, Colleen, and I talked about how your confidence is growing in engaging in play with other children. I noticed you having fun doing some ballet dance moves with new friends Sarah and Tia. You showed integrity and respect to put yourself out there to communicate with your peers and be part of the kindergarten community. Colleen shared with me that your confidence is developing from being guided or encouraged to play with others to you starting to establish and ask to play with others, especially when your main friends, Eva and Haeata, are not at Kindergarten. Ella, it was indeed lovely to see you building on your relationships with others by using your voice - "Can I play?" "Will you play with me?" "Want to join?" - to ask to be part of the dance and inviting others to play or join you.

3. I see that Vanessa has written about your interest in exploring and your ability to persist with challenges and problem solve when doing puzzles. Charlotte has also mentioned to me about these attitudes and skills that you hold. I have seen for myself all of these things happening within the short time I have known you. Here you are systematically working through each puzzle on the pages of an exploration activity book. As you work through the book I notice you demonstrate problem-solving skills such as using the picture cues to undercover what you need to do, locate where objects are, and through a process of trial and error you investigate which way to go to get to a certain distinction within a maze. When you accomplished your desired goal you exclaimed, "I made it!"

Such triangulation can authenticate the validity of an observation, that is, its utility for making inferences about a child's learning. In the examples above, more than one teacher had noticed a similar learning event at different times in terms of form and context, contributing to reliability by demonstrating consistent observations of learning over time (Snow \& Van Hemel, 2008).

The style of learning stories, which use the first person, with thoughts and feelings intertwined (Hazard, 2011), signifies that observations are partly subjective (Blaiklock, 2008, 2010; Zhang, 2017). That is, documented observations not only give the facts of what the

\footnotetext{
${ }^{1}$ All names have been changed to protect the anonymity of teachers and children.
} 
teacher is seeing and hearing but also making visible their perceptions of children's ideas, theories, and feelings (Hazard, 2011). This raises a fundamental question concerning validity: did a teacher accurately document what they observed (Johnson \& Christensen, 2017) or did they "try to see what they 'wanted' to see" and hear? (Emilson \& Pramling Samuelsson, 2014, p. 184). To mitigate the risk of the latter, teachers should not set out to look for particular aspects of learning (Hazard, 2011). To do so risks fitting children's behaviour to a template of what they want or expect to see, rather than understanding what is actually occurring. Instead, teachers should observe and listen as observations emerge to capture significant learning moments that they deem to be exciting such as a child engaging in a new learning experience or challenge (Hazard, 2011) e.g., difficulties in engaging with peers. In addition to sharing observations with their teaching teams, to corroborate their (subjective) interpretations of their observations, the actual words of children can be included (Carr \& Lee, 2019), thus providing credible and description-rich evidence for interpretative validity (Johnson \& Christensen, 2017). For example, an observer could ask children about what they are doing before saying what they think it is themselves.

\section{Recognise - Do you understand my story?}

The second component in the learning story framework is the analysis of learning. This relates to the recognise phase of a learning story - which usually relies on an educator's voice, either a teacher (Carr \& Lee, 2019) or a parent/carer depending who is writing the story. Interpretative analysis of observations (learning) recognises dispositions as being learning outcomes (Blaiklock, 2008; Carr, 2001; Carr \& Lee, 2019; MoE, 2017) which are positioned within the strands and goals of Te Whäriki. The attainment of learning dispositions can be characterised as 'learning how to learn'; a blend of emerging attitudes, knowledge and skills is important to the construction of a child's identity as a learner (Carr, 2001; Carr \& Lee, 2019; MoE, 2017). For example, an inclination to learn that encompasses being ready (motivated and interested) and willing (encouraging self-assessment) to learn indicates a child's ability to engage in an activity (Carr, 2001; Carr \& Claxton, 2002; Carr \& Lee, 2019; MoE, 2017).

Dispositions have been defined as the "motivation-participation repertoires from which a learner recognises, selects, edits, responds to, resists, searches for and constructs" skills and knowledge (Carr, 2001, p. 21). By definition, dispositions impact, negatively and positively, on the way in which children approach learning (Sadler, 2002), and therefore on their learning achievements (skills and knowledge). Hence, positive learning dispositions are important for setting children up for success in later education (Brooker, 2002). In support of this point, Cullen's (1991) observations showed the importance of key dispositions such as curiosity, task persistence and communication. Cullen revealed that children who acquire these behaviours in early education not only maintain them throughout Year 1 of primary school but also experience easier transitions to formal school learning and greater rates of school achievement than children with low use of learning strategies. Significantly, the disposition of taking an interest has been found to enhance cognitive development and performance (see Hidi, 1990 for review of literature). Not all dispositions enhance learning; some, such as 'impulsiveness' or 'close-mindedness' may hinder or interfere (Katz, 2002). Identifying such negative dispositions may be helpful to pinpointing the sources of children's learning difficulties.

The focus in ECE assessment on learning dispositions (Cameron, 2018; Carr, 2001; MoE, 2017) raises a significant concern regarding the validity of learning stories. The involvement of human judgement in the assessment of learning always entails human error. 
Furthermore, a challenge to validity arises from the fact that judgements are based on recorded observational information which is 'situation-specific' (Blaiklock, 2011, p. 7; Carr \& Lee, 2019) and founded on a subjective interpretation of a child's experience: Both the extent to which a child's experience has been correctly inferred and the extent to which judgements of learning dispositions are applicable in different contexts and at different times are questionable (Blaiklock, 2008). Three strategies can be utilised to address these threats to validity: seeking peer review, taking multiple perspectives, and obtaining feedback.

Peer review is a process that is fundamental to providing informed, insightful and indepth understandings of learning. It is essentially a form of social moderation - it involves discussing and reflecting with other teaching staff an interpretation of a child's learning experience. In doing so, each member of a teaching team has the opportunity to read and review an analysis of learning, to comment on the dispositions associated with the observed behaviour, and to check for inconsistencies.

Peer review is often accompanied by a strategy called multiple perspectives, under which consideration is given to alternative interpretations through shared ideas and explanations of information (see Johnson \& Christensen, 2017; Maxwell, 2013). Unlike multiple observations, this strategy does not necessarily involve more than one person directly interacting with a child, and is therefore not susceptible to the same practical and social constraints. It has been argued that, under this approach "objectivity is gained through making multiple voices visible" (Hatherly \& Sands, 2002, p. 10). While the claim for establishing objectivity may be overstating what is possible, it is nonetheless true that multiple perspectives are more likely than a single perspective to yield an accurate account of the dispositions associated with the behavioural evidence.

During reflective discussions, staff can debate and come to an agreement on what constitutes evidence for a construct, that is, "the behaviours that indicate particular dispositions" (Carr, 2001, p. 183). This may lead to a re-wording of descriptions of dispositions and the development of a rich new perspective on a child's learning. Interpretations of learning experiences through the process of re-checking findings with team members therefore helps to represent more accurately an insightful and in-depth understanding of a child's story. As a teacher interviewed for Zhang's (2017) study noted, "sometimes you don't see what [children] are learning but other teachers do." (p. 260). The reliability of an analysis is less questionable if team members are in a position to confirm the learning dispositions evinced by observational evidence through joint examination of the information. Furthermore, when different assessors (teachers) infer the same learning dispositions from the (observational) information in the learning story, the view of the author (teacher) of the story is reinforced, thus increasing its reliability and validity.

Even so, care is needed when drawing conclusions from observations. As noted by Dunn (2000), the extent to which a child's behaviour in a specific learning situation is typical of how that child operates may be unclear. To validate dispositional claims in an analysis, behaviours therefore need to be viewed at different times and in different contexts (e.g., an ECE setting and a home setting; Carr \& Lee, 2019). By collecting and reviewing multiple learning stories (observations) teachers are in a better place to verify whether what they are seeing and hearing represents "a reliable picture" of a child's learning orientation (Dunn, 2000, p. 79).

It is obviously impossible for a teacher to observe every moment of a child's learning in the course of a day (Blaiklock, 2008; MoE, 2004a) and, in any event, doing so would not be productive; not every learning moment yields useful observational evidence. Instead, 
feedback strategies can be utilised to enhance the plausibility and reliability of a teacher's inferences of a child's learning dispositions from a learning story. Feedback from a child and from his or her parents is an effective strategy for explicating recurring patterns of behaviour that can be used to support a teacher's analysis.

Having children provide feedback on their learning stories yields the additional benefits of encouraging self-assessment (Mitchell, 2008) and of enabling them to communicate what matters to them as learners (Cameron, 2018; MoE, 2017). Parental feedback is also an essential element of building a reliable picture of a child; it may confirm behaviour at home, or elsewhere, similar to that observed by a teacher, thus providing an indication of consistency. The inclusion of both child and parental voice in the analysis of learning can therefore verify the transferability of a teacher's findings to other contexts and times and create an assessment culture in which partnerships with children and their parents are valued (Carr \& Lee, 2019). This can occur only if teachers do not force their knowledge and interpretations before children and parents have put forward their questions and made their theories (Carr, 2001; see also MoE, 2004c).

Feedback from children and parents is often sought (see Cameron, 2018) by reading observational notes to the child and his or her parents which are frequently accompanied by photographs of moments in the learning process, and then inviting them to comment or add their perspectives before writing up a final version of a learning story. Recent research studies in NZ (e.g., Beaumont-Bates, 2017; Gallagher, 2018; Goodman \& Cherrington, 2015, 2017; Higgins \& Cherrington, 2017; Hooker, 2015; Penman, 2014) revealed that such parental contribution can be considerably enhanced through the use of digital learning story portfolios compared to paper-based portfolios, mainly because assessment is accessible in 'real-time' through online portfolios (Goodman \& Cherrington, 2015; Hooker, 2015). The rationale for these discussions is not only to authenticate teachers' interpretations of a child's learning but also to provide alternative insights to those of teachers (Carr, 2001; MoE, 2017; see also Snow \& Van Hemel, 2008). It is important to note, however, that reliable feedback from a child depends on his or her ability to communicate. Children with cognitive or verbal impairments may require additional resources such as communication boards to convey their thoughts and feelings about their learning. Children's perspectives on learning may also be made visible through photos and drawings (Duncan \& Eaton, 2013).

\section{Respond - Do you get where I am going with my story?}

The third component of the learning story process is to identify opportunities and possibilities - Respond - in other words, to decide what is next in the learning journey of a child (Cameron, 2018; Carr, 2001; Carr \& Lee, 2019). A child usually makes this decision for himself or herself (MoE, 2004a), with responses from the teaching team and parents contributing to this decision (Carr, 2001; Carr \& Lee, 2019; Hazard, 2011; MoE, 2017; Snow \& Van Hemel, 2008). A programme that involves a child's identified interests, strengths, capabilities and areas in learning that need support (Zhang, 2017) is then developed.

This is where threading a child's learning challenges through their story could make a positive contribution to future learning. By capturing moments of difficulty in learning - such as task avoidance and repeated failure after using various trial and error strategies - it may be possible to pinpoint situations in which a child "will be more likely to close himself or herself off from ... learning opportunities and a deeper understanding of the world" (Dunn, 2000, p. 74). For a child to successfully continue to practise a concept or skill and to persist 
when they encounter difficulties, they need to have "positive learning experiences" (Dunn, 2000, p. 81) as well as a positive attitude towards learning.

Carr and Claxton (2002) argued that if a child is not positively inclined towards learning then limited learning will transpire. To foster a robust orientation towards learning, positive learning dispositions identified in the analysis are transformed into actions for further learning (Sadler, 2002). For example, the learning disposition 'responsibility' (manifested as taking responsibility and sharing experiences with others), from a story about showing respect and kindness, can be put into action by, for example, providing "multiple opportunities" (Snow \& Van Hemel, 2008, p. 286) to engage with group games that involve turn-taking and sharing, helping out with routines and helping peers. Planning for further learning draws attention to a child's learning strategies "to encourage the desire to try something out, to engage in an activity, to keep trying, etc" (Dunn, 2000, p. 80) as illustrated by the example above.

Plans can be developed from a child's interests, strengths and capabilities observed during the Notice component of the learning story process, to strengthen what is going well and to help to identify ways in which to overcome challenges in learning (Dunn, 2000; Williamson et al., 2006). This is achieved through the identification of activities and situations that lead "a child to successful learning experiences and use those features to guide the introduction of further experiences" (Dunn, 2000, p. 80). A child's positive dispositions, interpreted via the learning assessment information in the Recognise component, are then translated into teaching strategies that support his or her interest-based goals to motivate and enhance learning (Dunn, 2000). For example, the disposition of 'responsibility' could be converted into a teaching strategy of guiding a child to develop leadership skills. Such a strategy could support the child's interest in sharing experiences with others by, for example, showing him or her how to lead a waiata (Māori song) and perform a haka (Māori war dance) when families are welcomed to the centre. Such an approach might develop more positive learning dispositions such as 'courage' and 'confidence' as well as improving performance.

Learning stories that incorporate children's current struggles and challenges alongside their strengths could positively influence planning for further learning in three main ways. First, they could act as scaffolding towards independent learning by documenting children's abilities (Carr, 2001) - what children cannot yet do on their own without support and resources as well as what they can accomplish without intervention (Carr \& Lee, 2019). Second, they could serve the improvement of motivation by documenting 'readiness' - an interest to try something that they are not yet able to accomplish (Carr, 2001; Carr \& Lee, 2019) - inferred from an inclination (MoE, 2017) to find out more, to go deeper and to develop more complex and sophisticated skills. Third, they could encourage self-assessment by documenting a 'willingness to try' (Carr, 2001), inferred from a child initially setting a goal, by making visible their ideas, thinking and learning strategies (dispositions) used to support and shape their approach to that goal (Carr \& Lee, 2019; MoE, 2017).

Assessment decisions have a profound influence on planning for children's further learning and development (McLachlan, Edwards, Margrain, \& McLean, 2013). It is therefore essential that such decisions are based on valid and reliable evidence, to inform effective plans for next steps in learning. To make well-founded educational decisions requires a shared effort - and learning stories are designed to be shared (Blaiklock, 2008; Cameron, 2018; Carr \& Lee, 2019; Dunn, 2000; Hazard, 2011; Zhang, 2017). The act of sharing in the context of assessment refers to "transparency, collaboration" (Dunn, 2000; Hazard, 2011, p. 14) and a joint responsibility (Black \& Wiliam, 2009; Macy et al., 2016; Williamson et al., 2006). Peer 
review and gathering appropriate feedback from parents and children are strategies that can be used to enhance the clarity of an assessment. Hence, learning stories provide a vehicle for multiple perspectives (Cameron, 2014, 2018; Carr, 2001; Carr \& Lee, 2019) from all members of an educational team: children, parents and ECE teachers; this may also include early intervention teachers, education support workers and other specialists depending on individual children's needs (Macy et al., 2016).

Dialogue with team members is an important part of the learning story process (Blaiklock, 2008; Cameron, 2018; Carr \& Lee, 2019; see also Zhang, 2017) as it provides a forum to develop agreement about the planning of goals and strategies to extend a child's learning journey (Williamson et al., 2006; see also Carr \& Lee, 2019). The perspective of any one team member (teacher, parent or child) alone is much more prone to error than a perspective developed through critical dialogue (Johnson \& Christensen, 2017; Maxwell, 2013). Such dialogue therefore increases the likelihood that a child's future directions will be informed by accurate analysis of learning-story information.

The multiple perspectives strategy is essential for the creation of shared language to describe children's learning and development, which in turn enables everyone to contribute equally (Carr \& Lee, 2019; Williamson et al., 2006). As one parent commented in the research of Lepper et al. (2003): "With learning stories everyone is on an even playing field" (p. 20). Promoting "a community of practice" (Williamson et al., 2006, p. 22; see also Cowie \& Carr, 2017) requires all interested parties to be active participants, learners and communicators in the planning processes (MoE, 2017). In addition, learning story assessments are kept transparent by placing them in easy view and reach of children in ECE settings to give them direct access to their own stories (Carr, 2001; see also Hooker, 2015). The positive impact is that children can revisit experiences and reflect on their work by interpreting photos to find or decide upon new directions (see Carr \& Lee, 2019 for examples). In doing so, children are encouraged to take ownership and to be empowered "to steer their own course, set their own goals, assess their achievements, and take on some of the responsibility for learning" (MoE, 2004b, p. 2; see also Cameron, 2018). According to this view, children engage in selfassessment by reflecting on their own progress (what they can and cannot yet do) and deciding upon the next steps in their learning journeys (MoE, 2017). A future action that builds on prior learning can then be documented to make "progress over time" visible (MoE, 2017, p. 63) as stories become longer, wider, and more complex (Carr, 2001; see Carr \& Lee, 2019 for examples).

\section{Conclusion}

The use of learning stories as an assessment tool in the ECE sector is widespread in NZ. While it is a dynamic, strengths-based assessment model, grounded in sociocultural theory and community of practice, the approach could be enhanced by making visible children's learning challenges to better support the formative use of learning stories and to help children to establish resilience, persistence and independent dispositions in their learning. To avoid compromising the positive focus on children's interests, strengths and capabilities, challenges can be positioned in the 'background' of the stories. A rich description of a child's interests, strengths and capabilities that also incorporate learning struggles could positively influence planning for further learning in three main ways: Providing scaffolding towards independent learning, improving motivation, and encouraging self-assessment skills. 
High-quality learning stories 'notice' who a child is, 'recognise' what matters to them by understanding their learning strategies, and 'respond' by making visible the road they are going on for their unique learning journey. To instil confidence and trust in the potential for learning stories to contribute to planning for further learning, some effective strategies to enhance the reliability and validity of learning stories were discussed. These included watchful listening and teachers informally sharing observations arising from the Notice component and the use of children's own words. The Recognise component could benefit from peer review, the use of multiple perspectives, and child and parental feedback. The Respond componentcritical from a formative perspective - could be made more reliable with multiple perspectives, i.e., those of children and parents in addition to those of teachers. None of the strategies suggested here are by any means new to the teaching profession. However, we argue that if implemented collectively they are likely to enhance the validity of the learning story method to better provide "robust and insightful" assessment information to support planning for children's further learning (Cameron, 2014, p. 31).

We are not advocating that learning stories are the only, or even the best, assessment methodology of ECE (a sentiment endorsed by Hazard, 2011; Zhang, 2015). Nevertheless, given that they are currently the main adopted method in NZ, we argue that for this assessment to be effective for planning for children's learning growth, the approach needs to provide plausible and reliable formative information. Consequently, this requires much time and effort on the part of ECE teachers - many of whom are already stretched for time - noted by Mitchell's (2008) and Cameron's (2018) studies of ECE assessment practices. To support teachers therefore, it is important for MoE funding to be made available for on-going professional learning and development (PLD) aimed at ECE services. Such PLD is required to ensure that all teachers can critically reflect on, and effectively utilise the strategies to implement learning stories to their "full potential" (see Cameron, 2014, 2018, p. 94; Cameron et al., 2016). It is the responsibility of every teacher to seek PLD opportunities in order to enhance their practice in respect of each stage of the learning story framework - notice, recognise and respond. Thereby, the capacity of learning stories to provide sound assessment information to support effective planning for children's future learning can be continually enhanced.

\section{References}

Absolum, M. (2011). Clarity in the classroom: Using formative assessment for building learning-focused relationships. Winnipeg, Canada: Portage \& Main Press.

Beaumont-Bates, J. (2017). E-Portfolios: Supporting collaborative partnerships in an early childhood centre in Aotearoa/New Zealand. New Zealand Journal of Educational Studies, 52(2), 347-362. doi.10.1007/s40841-017-0092-1

Black, P., \& Wiliam, D. (2009). Developing the theory of formative assessment. Educational Assessment, Evaluation and Accountability, 21(1), 5-31. doi.10.1007/s11092-0089068-5.

Blaiklock, K. E. (2008). A critique of the use of learning stories to assess the learning dispositions of young children. New Zealand Research in Early Childhood Education, 11, 77-87.

Blaiklock, K. E. (2010). Assessment in New Zealand early childhood settings: A proposal to change from learning stories to learning notes. Early Education, 48, 5-10. 
Blaiklock, K. (2011). Curriculum guidelines for early literacy: A comparison of New Zealand and England. Australasian Journal of Early Childhood, 36(3), 3-9.

Brooker, L. (2002). Starting school: Young children learning cultures. Buckingham, England: Open University Press.

Cameron, M. (2014). Keeping learning stories complex:. A call for ongoing critique. Early Education, 55, 30-31.

Cameron, M. (2018). Assessing four-year-old children's learning: New Zealand early childhood teachers' purposes, practices and beliefs (Doctor of Education thesis). Massey University, Palmerston North, New Zealand.

Cameron, M., McLachlan, C., \& Rawlins, P. (2016). 'Assessment in ECE is overwhelming at times': Uncovering the challenges of assessing four year old children's learning. Early Education, 60, 12-16.

Carr, M. (1998). Assessing children's learning in early childhood settings: A professional development programme for discussion and reflection. Wellington: New Zealand Council for Educational Research.

Carr, M. (2001). Assessment in early childhood settings: Learning stories. London: Paul Chapman.

Carr, M., \& Claxton, G. (2002). Tracking the development of learning dispositions. Assessment in Education: Principles, Policy \& Practice, 9(1), 9-37. doi.10.1080/09695940220119148

Carr, M., \& Lee, W. (2019). Learning stories in practice. London, England: SAGE.

Cowie B., \& Carr M. (2017). Narrative assessment: A sociocultural view. In M. A. Peters (Eds), Encyclopedia of educational philosophy and theory. Singapore: SpringerLink.

Cullen, J. (1991). Young children's learning strategies: Continuities and discontinuities. International Journal of Early Childhood, 23(1), 44-58. doi.10.1007/bf03174607

Drummond, M. J. (1993). Assessing children's learning. London: David Fulton.

Duncan, J., \& Eaton, S. (2013). A rhizomatic experiment with learning stories. Global Studies of Childhood, 3(3), 318-327. doi.10.2304/gsch.2013.3.3.318

Dunn, M. L. (2000). Using "learning stories" to assess and design programs for young children with special needs in New Zealand. Infants \& Young Children, 13(2), 73-82. doi.10.1097/00001163-200013020-00012

Dunn, L. (2004). Developmental assessment and learning stories in inclusive early intervention programmes: Two constructs in one context. New Zealand Research in Early Childhood Education, 7, 119-133.

Eden, R. (2015). Keryn Davis, Jocelyn Wright, Margaret Carr and Sally Peters: Key competencies, assessment and learning stories: Talking with teachers and students. New Zealand Journal of Educational Studies, 50(1), 165-167. doi.10.1007/s40841015-0016-x

Emilson, A., \& Pramling Samuelsson, I. (2014). Documentation and communication in Swedish preschools. Early Years, 34(2), 175-187. doi.10.1080/09575146.2014.880664

Forman, G., \& Hall, E. (2013). Wondering with children: The importance of observation in early education. LEARNing Landscapes, 7(1), 187-202. Retrieved from https://learninglandscapes.ca/index.php/learnland/article/view/Wondering-WithChildren-The-Importance-of-Observation-in-Early-Education

Gallagher, A. (2018). E-portfolios and relational space in the early education environment. Journal of Pedagogy, 9(1), 23-44. dDoi.10.2478/jped-2018-0002 
Goodman, N., \& Cherrington, S. (2015). Parent, whānau, and teacher engagement through online portfolios in early childhood education. Early Childhood Folio, 19(1), 10-16. doi.10.18296/ecf.0003

Goodman, N., \& Cherrington, S. (2017). Children's engagement with their learning using eportfolios. Asia-Pacific Journal of Research in Early Childhood Education, 11(3), 1738.

Hatherly, A., \& Sands, L. (2002). So what is different about learning stories. The First Years: Nga Tua Tuatahi. New Zealand Journal of Infant and Toddler Education, 4(1), 8-12.

Hazard, M. (2011). Learning stories: One way to assess and report - professionals and children working together. Every Child, 17(3), 14-15.

Hidi, S. (1990). Interest and its contribution as a mental resource for learning. Review of Educational Research, 60(4), 549-571. doi.10.2307/1170506

Higgins, A., \& Cherrington, S. (2017). What's the story? Exploring parent-teacher communication through ePortfolios. Australasian Journal of Early Childhood, 42(4), 13-21. doi.10.23965/AJEC.424.02

Hooker, T. (2015). Assessment for learning: A comparative study of paper-based portfolios and online ePortfolios. Early Childhood Folio, 19(1), 17-24. doi.10.18296/ecf.0004

Johnson, B., \& Christensen, L. B. (2017). Educational research: Quantitative, qualitative, and mixed approaches ( $6^{\text {th }}$ ed.). Thousand Oaks, CA: SAGE.

Katz, L. (2002). 'Not all dispositions are desirable': Implications for assessment. Assessment in Education: Principles, Policy \& Practice, 9(1), 53-54.

doi.10.1080/09695940220119175

Lepper, C., Williamson, D., \& Cullen, J. (2003). Professional development to support collaborative assessment. Early Education, 33, 19-28.

Macy, M., Bagnato, S., \& Gallen, R. (2016). Authentic assessment: A venerable idea whose time is now. ZERO TO THREE, 37(1), 37-43

Maxwell, J. A. (1992). Understanding and validity in qualitative research. Harvard Educational Review, 62(3), 279-300.

Maxwell, J. (2013). Qualitative research design: An interactive approach (3 ${ }^{\text {rd }}$ ed.). Applied Social Research Methods Series, 41. Thousand Oaks, CA: SAGE.

McLachlan, C., Edwards, S., Margrain, V., \& McLean, K. (2013). Children's learning and development: Contemporary assessment in the early years. South Yarra, VIC: Palgrave Macmillan.

Ministry of Education. (2017). Te whāriki: He whāriki mātauranga mō ngā mokopuna o Aotearoa: Early childhood curriculum. Wellington, New Zealand: Author.

Ministry of Education. (2004a). Kei tua o te pae: Assessment for learning: Early childhood exemplars. Book 1: An Introduction to kei tua o te pae. He whakamōhiotanga ki kei tua o te pae. Wellington, New Zealand: Author.

Ministry of Education. (2004b). Kei tua o te pae: Assessment for learning: Early childhood exemplars. Book 4: Children contributing to their own assessment. Ngā huanga tamariki ki tō rātou aromatawai. Wellington, New Zealand: Author.

Ministry of Education. (2004c). Kei tua o te pae: Assessment for learning: Early childhood exemplars. Book 5: Assessment and learning: Community. Te aromatawai me te ako: Hapori. Wellington, New Zealand: Author.

Mitchell, L. (2008). Assessment practices and aspects of curriculum in early childhood education results of the 2007 NZCER national survey for ECE services. Wellington, New Zealand: New Zealand Council for Educational Research. 
Newton, P. E., \& Shaw, S. D. (2014). Validity in educational and psychological assessment. London: Sage.

Penman, R. (2014). E-portfolios: Connecting parents, whanau and teachers in kindergarten communities. Early Education, 56, 10-13.

Sadler, D. R. (2002). Learning dispositions: Can we really assess them? Assessment in Education: Principles, Policy \& Practice, 9(1), 45-51. doi.10.1080/09695940220119166.

Snow, C., \& Van Hemel, S. (2008). Early childhood assessment why, what, and how. Washington, DC: National Academies Press.

Te Kete Ipurangi. (n.d.). Retrieved from http://assessment.tki.org.nz/Gathering-and-usingevidence-for-learning/Working-with-data/Concepts/Reliability-and-validity.

Vygotsky, L. S. (1978). Mind in society: The development of higher pyschological processes. London: Harvard University Press.

Williamson, D., Cullen, J., \& Lepper, C. (2006). Checklists to narratives in special education. Australian Journal of Early Childhood, 31(2), 20-29.

Zhang, Q. (2015). Advocating for a comprehensive approach to assessment in New Zealand early childhood education. New Zealand Research in Early Childhood Education, 18, 67-79.

Zhang, Q. (2017). Do learning stories tell the whole story of children's learning? A phenomenographic enquiry. Early Years, 37(3), 255-267. doi.10.1080/09575146.2016.1151403

Louise Wanoa is a postgraduate student at Victoria University of Wellington and has worked in teaching, tutoring and mentoring roles in education since 2002 both within the early childhood field and the adult education sector. Her interests centre on educational assessment, student learning, mentoring and coaching, inclusion, and professional learning.

Email: wanoaloui@myvuw.ac.nz

ORCID: http://orcid.org/0000-0003-4049-6736

Dr Michael Johnston is Associate Dean (Academic) in the Faculty of Education at Victoria University of Wellington. His research interests centre on the impact of assessment on teaching and learning. He also contributes to public policy on assessment through membership of a number of advisory groups to education agencies.

Email: michael.johnston@vuw.ac.nz

ORCID: http://orcid.org/0000-0001-5319-5890 